\title{
Schwannoma intercostal simulando neoplasia pulmonar
}

\author{
L.A. Henn, R.V. Gonzaga, J . Crestani, M.R. Cerski \\ Hospital de Clínicas de Porto Alegre, RS.
}

RESUMO - Schwannoma é uma neoplasia mesenquimal, usualmente solitária, encontrada no mediastino, retroperitônio ou pelve, sendo rara sua apresentação na parede torácica.

Oвj etivo. Relatar o caso de um paciente masculino, tabagista, com um nódulo pulmonar direito com características de malignidade, detectado em radiografia de tórax de rotina, cujo diagnóstico anatomopatológico foi de schwannoma benigno de nervo intercostal.

Métodos. Revisaram-se os dados referentes ao quadro clínico, exames laboratoriais e de imagem (radiografia e tomografia computadorizada de tórax) do caso em estudo, assim como os exames anatomopatológico e imuno-histoquímico do espécime cirúrgico.

Resultados. O paciente foi submetido à toracotomia direita diagnóstica com ressecção da tumoração. 0 exame anatomopatológico convencional mostrou células tumorais de aspecto fusi-

\section{NTRODUÇÃO}

O schwannoma é uma neoplasia mesenquimal relativamente rara originada das células de Schwann da bainha dos nervos. É, usualmente, encontrado no mediastino, retroperitônio ou pelve, raramente ocorrendo na parede torácica ${ }^{1-5}$.

Relatamos o caso de um paciente de 64 anos, masculino, tabagista, com um nódulo projetandose no ápice do pulmão direi to simulando um tumor maligno, detectado por radiografia de tórax de rotina. Após a ressecção do tumor, o diagnóstico definitivo mediante exame anatomopatológico foi de schwannoma benigno. E ste estudo propõe-se a revisar os achados clínicos, aspectos patológicos, métodos diagnósticos e tratamento desse tumor.

\section{APRESE NTAÇÃO DO CASO}

Paciente de 64 anos, masculino, tabagista por 54 anos (108 carteiras/ano), internou-se para investigar um nódulo no ápice do pulmão direito, evidenciado por radiografia de tórax de rotina, que mostrou uma opaci dade com diâmetro de $2,5 \mathrm{~cm}$ no lobo superior do pulmão direito, confirmado por forme, dispostas em paliçada, formando os corpos de Verocay, compatível com schwannoma intercostal. A imuno-histoquímica foi positiva para proteína S-100, vimentina e enolase, e negativa para neurofilamentos.

Conclusão. $O$ diagnóstico definitivo de schwannoma só é possível por meio da análise histopatológica e imuno-histoquímica da lesão. Seu aspecto celular, associado à atividade mitótica e a áreas de pleomorfismo, pode levar ao diagnóstico incorreto de malignidade. A imuno-histoquímica, por meio da proteína S-100, é útil na caracterização da beni gnidade da lesão, já que não é detectada nas lesões malignas. Os schwannomas de parede torácica podem simular neoplasias pulmonares na radiografia e tomografia computadorizada de tórax.

UNITERMOS: Schwannoma. Neurilemoma. Tumores da parede torácica. Tumores intercostais.

tomografia computadorizada (TC), que sugeriu uma origem pleural. Apresentava dispnéia aos médios esforços, e dor, parestesias, fraqueza e restrição dos movimentos no ombro direito. Negava tosse, hemoptise, perda de peso ou nódulos subcutâneos pal páveis na parede torácica.

Nova Tc de tórax (fig. 1) sugeriu que o nódulo poderia ser extrapleural, devido à visualização de um pedúnculo conectando o nódulo à parede torácica, sem envolvimento dos arcos costais. Exame citológico do escarro (três amostras) foi negativo para células malignas.

O paciente foi submetido à toracotomia direita diagnóstica com ressecção da tumoração. O diagnóstico anatomopatológico convencional foi de schwannoma benigno (fig. 2). A imuno-histoquímica foi reativa para proteína S-100, vimentina e enolase, e negativa para neurofilamentos.

\section{DISCUSSÃO}

Schwannomas benignos e neurofibromas são tumores originados da bainha dos nervos, correspondendo a mais de $60 \%$ dos tumores neurogêni cos toráci $\cos ^{3}$. Schwannoma ou neurilemoma é uma 

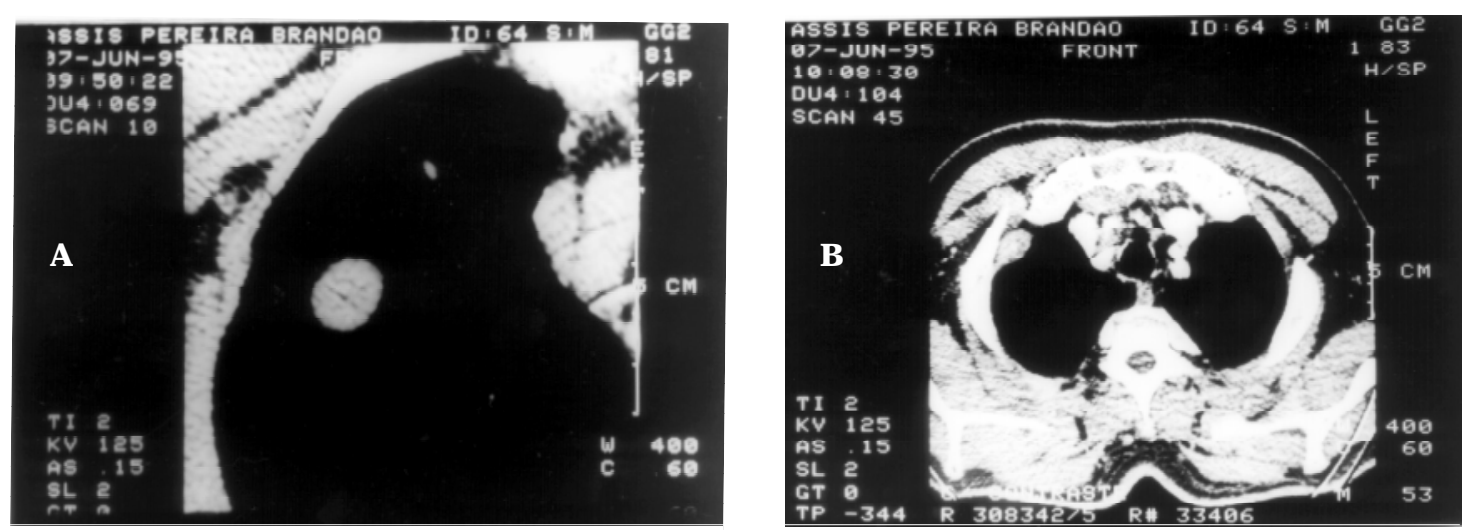

Fig. 1 - Tomografia computadorizada de tórax: A) nódulo no ápice do pul mão direito medindo cerca de 2,5cm de diâmetro; B) pedúnculo conectando o nódulo ao primeiro arco costal, sem sua destruição.

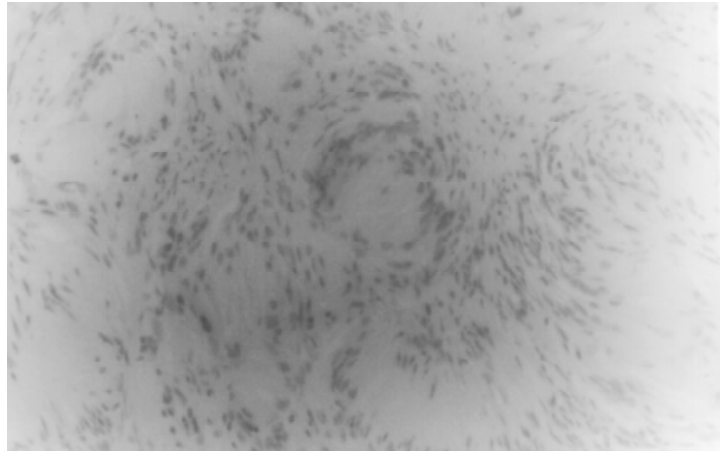

A

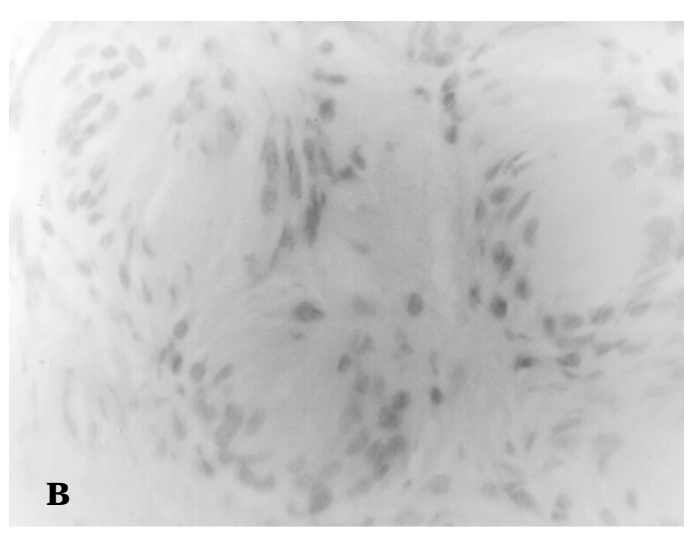

Fig. 2 - Microscopia do schwannoma: A) células tumorais fusiformes dispostas em paliçada ou formando os corpos de Verocay (tipo Antoni A). HE, 20x; B) área celular com pleomorfismo nuclear e corpos de Verocay. HE, 40x. neoplasia encapsulada que se origina das células de Schwann da bainha dos nervos freqüentemente solitária quando de localização intratorácica e múltipla quando extratorácica ${ }^{1,3,4}$. Localiza-se mais comumente no mediastino e/ou retroperitônio e/ou pel ve $2,4,5,8$. No tórax, a local ização mais comum dos tumores neurogênicos é no mediastino posterior ${ }^{2,3}$. No estudo de Harjula, 64 de 66 casos foram encontrados nessa área ${ }^{2}$. Raramente ocorre no mediastino anterior (6\%), no parênquima pulmonar (2\%) e na parede torácica lateral $(5 \%)^{3}$.

Esses tumores são, usualmente, detectados entre a terceira e quinta décadas de vida, com igual incidência em homens e mulheres $2,5,6,8$.

Os tumores neurogênicos intratorácicos são quase sempre assintomáticos, sendo detectados em exames radiológicos de rotina em $66-78 \%$ dos $\operatorname{casos}^{1-3,7}$. Quando presentes, os sinais e sintomas mais comuns são dor, tosse, dispnéia, perda de peso, fraqueza, febre, hipertensão, vertigem, disfagia, dependendo do sítio anatômico envolvido².

A TC é um exame útil na identificação de lesões múltiplas, porém apresenta valor limitado em identificar sua natureza extrapleural, quando a ressonância nuclear magnética é o melhor méto$\mathrm{do}^{3}$. Pode-se tentar diagnosticar a natureza da lesão mediante biópsia aspirativa com agulha fina ${ }^{1,6}$. Caso essa não seja conclusiva, o procedimento seguinte é a retirada do nódulo para avaliação por congelação e/ou exame anatomopatológi co convencional, a fim de determinar a malignidade ou benignidade do tumor ${ }^{1}$.

Patologicamente, os schwannomas são circunscritos, variando de $0,7-7 \mathrm{~cm}$ de diâmetro, podendo apresentar áreas císticas ${ }^{4-6,8}$. Microscopicamente, dois padrões teciduais diferentes podem ser reconhecidos, designados Antoni A e Antoni B. O tecido Antoni A é mais típico dos schwannomas, sendo composto por cél ulas fusiformes dispostas em paliçada ou formando os corpos de Verocay. Antoni B é um tecido mixomatoso e degenerativo, contendo poucas células e uma abundante matriz separando essas das fibras tumorais, formando espaços císticos ${ }^{4,6,8}$. Alguns tumores podem apresentar ativi- 
dade mitótica, pleomorfismo nuclear e hipercromasia, particularmente em áreas de alterações degenerativas, levando a um diagnóstico errôneo de malignidade ${ }^{5,8}$. A presença de vasos sanguíneos pode simular uma neoplasia vascular ${ }^{1,4-6}$. Transformação maligna ocorre em aproximadamente 3$10 \%$ dos casos, apresentando grande proliferação celular, atividade mitótica atípica, pleomorfismo celular e nuclear e focos de necrose, e uma maior associação com a doença de von Recklinghausen ${ }^{1,5}$.

A imuno-histoquímica por meio da proteína S100 é outro recurso utilizado na identificação dos schwannomas e caracterização de sua malignidade ou benignidade, pois, em tecidos moles fora do sistema nervoso central, ela é encontrada apenas em células de Schwann e melanócitos, não sendo detectada em schwannomas malignos ${ }^{4,5,7}$. A reatividade dos schwannomas à proteína S-100 e neurofilamentos é de aproximadamente $97 \%$ e $20 \%$, respectivamente, apresentando uma reatividade difusa à vimentina ${ }^{5,7}$.

A pós o diagnóstico definitivo de benignidade, o tratamento de escol ha é a cirurgia com excisão do nódulo tumoral, preservando ou não o nervo de origem do tumor, dependendo da sua importância ${ }^{1,2,6-8}$. A recorrência tumoral é baixa, havendo uma significativa associação com o grau de contagem mitótica.

\section{CONCLUSÃO}

A principal razão para o diagnóstico do schwannoma é o fato de que sua celularidade, associada com atividade mitótica atípica e focos de pleomorfismo, pode levar a um diagnóstico incorreto de malignidade, resultando em cirurgia agressiva ou irradiação desnecessária ${ }^{5}$. Em exames de imagem, as lesões podem simular tumores pulmonares parenquimatosos ou pleurais, sendo o diagnóstico definitivo, muitas vezes, confirmado somente com a toracotomia e exérese tumoral.

\section{AGRADECIMENTO}

Os autores agradecem ao Dr. Nestor E. Zuluaga, por sua parti ci pação no diagnóstico e tratamento do paciente.

\section{SUMMARY}

\section{Intercostal schwannoma simulating pulmonary neoplasia}

Schwannoma is a mesenchymal neoplasm, fre quently solitary, localizated in the mediastinum, retroperitoneum or pelvis, being rare in the thoracic wall.
Purpose. Describe the case of a man, tabagist, with a nodulein right lung that showed malignant characteristics detected by routine chest radiographs, whose histopathological diagnosis was benign intercostal schwannoma.

METHOD. The authors reviewed the clinical features, chest radiographs and computer tomographies of the case, and the histological and immunohistochemical aspects of the surgical specimen.

RESULTS. The patient was submitted to diagnostic right thoracotomy with resection of the tumor. The conventional histopathological exam showed spindle shaped cells in a palisading fashion, forming the Verocay's bodies, characteristics of schwannomas. The immunohistochemical was positive to S-100 protein, vimentin and enolases, and negative to neurofilament proteins.

ConCLUSION. The definitive diagnosis of schwannoma is possible only after histopathological and immunohistochemical examination of the tumor. Its cellularity associated with mitotic count and pleomorphism may lead to a mistaken diagnosis of malignant neoplasm. The immunohistochemistry by S-100 protein can characterize the benignity of the lesion, so that this protein is not found in the malignant cells. The intercostal schwannomas of the thoracic wall can mi mick pul monary neoplasm in chest radiographs and computer tomographies. [Rev Ass Med Brasil 1998; 44(2):146-8.]

KEY WORDS: Schwannoma. Neurilemoma. Tumors of the thoracic wall. Intercostal tumors.

\section{REFERÊ NCIAS BIBLIOGRÁFICAS}

1. Urakawa $\mathrm{T}$, Kawakita $\mathrm{N}$, Nagahata $\mathrm{Y}$. A case of benign schwannoma of the thoracic wall mimicking a malignant tumor. KobeJ Med Sci 1993; 39: 123-3l.

2. Harjula A, Mttila S, Luosto R, Kostiainen S, Mattila I. Medistinal neurogenic tumours. Scand J Thor Cardiovasc Surg 1986; 20: 115-8.

3. Murray RJ, Criner GJ, Siegel E. Multiple schwannomas presenting as a mass of the lateral chest wall. AJ R 1988; 151: 1.250-1.

4. Rosai J. Tumours of the soft tissue. Ackerman's surgical pathology. $2^{\text {nd }}$ ed. New York, Mosby, 1996; 2.042-5.

5. Fletcher CDM, Davies SE, Mvkee PH. Cellular schwannoma: a distinct pseudosarcomatous entity. Histopathol ogy 1987; 11: 21-35.

6. Dahl I, Hagmar B, Idvall I. Benign solitary neurilemoma (schwannoma). Acta Pathol Microbiol Immunol Scand 1984; 91: 91-101.

7. Casadei GP, Scheithauer BW, HiroseT et al . Cellular schwannomna: a clinicopathologic, DNA flow cytometric, and proliferation marker of 70 patients. Cancer 1995; 75(5): 1.109-19.

8. Woodruff] M, Godwin TA, Erlandson RA, Susin M, Martini N. Cellular schwannoma: a variety of schwannoma sometimes mistaken for a malignant tumor. Am J Surg Pathol 1981; 5: 733-44. 